\title{
Climate Variability and Gender: Emerging Experiences From Western Zambia
}

\author{
Catherine Lwando ${ }^{1}$ \\ ${ }^{1}$ Department of Geography, School of Natural Sciences, University of Zambia, Zambia \\ Correspondence: Catherine Lwando, Department of Geography, School of Natural Sciences, University of \\ Zambia, Box 32379, Lusaka, Zambia. Tel: 260-979-324-932. E-mail: cathylwando@yahoo.com
}

Received: September 12, 2013 Accepted: October 14, 2013 Online Published: November 22, 2013

doi: 10.5539/enrr.v3n4p133 URL: http://dx.doi.org/10.5539/enrr.v3n4p133

\begin{abstract}
Climate change is one of the greatest environmental challenges. It has posed a serious risk to poverty reduction and development, with adverse impacts expected on the environment, food security and natural resources. There is a strong link between gender and climate change and both are considered as cross cutting issues. However, climate variability and gender has been less attended to in terms of linking climate variability to the process of developing relevant environment and natural resource policies for natural resource dependent communities and most literature has lacked a reflection on the participation process of the natural resource dependent communities in the formulation and implementation of these policies especially at the local level and hence this study. This paper uses Sesheke district in Western Zambia and provides a case study of climate variability and genderand relates it to how the livelihoods of natural resource dependent women and men have been affected in the study area. It further reviews the participation of natural resource dependent communities and gender considerations in the formulation of key policies such as the agriculture and environmental policies in the face of climate variability and how these policies have been implemented in practice at the very local level in terms of a gender-responsive funding allocation and disbursement by government for adaptation activities at local level. The study shows that there has been a significant reduction in the annual rainfall from the year 1970 to 2010 and this has affected both men and women by forcing them to adapt to climate variability by using different means. Results show that climate variability has affected rural livelihoods and this has led to particular effects on gender roles. With regards to policy formulation related to agriculture and natural resources, results have shown that whilst the local people were consulted during the formulation of these policies and have taken into consideration the gender dimensions in terms of providing for the active participation of both women and men, the results have revealed an inadequate and unconsolidated approach to the implementation of the policies coupled with gender blind budgeting and poor funding disbursements to the district.
\end{abstract}

Keywords: climate variability, gender, policy, adaptation, livelihood

\section{Introduction}

Climate changerefers to any long-term change in the statistical distribution of weather patterns, whether in terms of changes in average conditions (more/less rainfall, higher/lower temperatures), or in the distribution of events around the average (extreme weather events such as floods or droughts). Generally, the term is used for any change in climate over time, regardless of cause, but the UN definition is more specific in using the term to denote changes that are attributable, whether directly or indirectly, to humanactivity (IPCC, 2007).

This paper provides a case study of climate variability and gender. The distinction between climate variability and climate change is one that has been made in several different ways. A common distinction, based on timescale, is to refer to climate variability as variations in the climate system over short timescales, for example months, years and decades, and to use climate change to describe longer term trends in mean climate variables of periods of decades or longer (Watson, 2001). In this study the terms climate variability and climate change will be used interchangeably in order to distinguish respectively between short term variations in the climate, of which extreme climate events such as droughts and high rainfall episodes that lead to flooding are manifestations, and longer term trends in climate revealed by changes in mean climate conditions over multiple-decades. 
Climate change is increasingly being recognized as a global crisis, but responses to it have so far been overly focused on scientific solutions, rather than on the significant human and gender dimensions as observed by Skinner (2011). Scholars have noted that women and men do not experience climate change equally. In most developing countries, women's livelihoods are centered particularly around climate sensitive sectors such as subsistence agriculture. The fact that women and girls are often responsible for most of the unpaid care tasks around the household also means that their lives are directly affected by the changes brought about by climate change. Women often have to walk further to find increasing scarce food, fuel wood and water as well as caring for family members who are susceptible to the health risks linked to climate change. As a result women and girls find themselves with less time for education, income generating activities or participation in community decision making processes, further entrenching unequal gender relations (Skinner, 2011).

Dankelman (2010) notes that although climate change affects everybody, it is not gender neutral.As weather patterns become increasingly unpredictable and extreme events such as floods, heat waves or natural disasters become more common, the poor in vulnerable communities find their livelihoods most threatened.Climate change affects women and men differently. According to the World Bank (2008), rural women and girls frequently provide households with water and firewood. The time needed for their work in gathering water and firewood has increased with water shortages and depletion of forests thereby decreasing the time available to women for food production and participation in income generating activities and this has affected household food security.

Aboud (2011) indicates that Climate change responses cannot be effective unless they are gender aware, taking into consideration the different needs of women and men, the inequalities that compound the impacts of climate change for women and the specific knowledge women and men can contribute to solutions. There is a strong link between gender and climate change and both are considered as cross cutting issues that needs to be integrated in national, local level planning as well as development cooperation initiatives by cooperating partners/donors. There is enough evidence to show that women are at the center of sustainable development, and that ensuring greater gender equalities in responding to climate change would mean that society as a whole will benefit (Denton, 2002).

The climate is naturally variable, but changes in mean climate conditions as a result of enhanced atmospheric warming are expected to be accompanied by changes in variability, including changes in the frequency or severity of some extreme climate events, such as heat waves, droughts, floods and storms (Goulden, 2006). It is these changes in climate variability and extremes that are expected to have negative impacts on human and natural systems (Watson, 2001). However, these impacts are expected to be differentiated according to differing levels of vulnerability between different sectors and groups within society (Adger et al., 2003).

Zambia and particularly the south western part of the country, the geographical focus of this study, lies on the periphery of the semi-arid environment of the Kalahari region such that it comprises a zone of very high risk to climate variability. This is because the region lies at the southern extremity of the migratory track of the Inter-Tropical Convergence Zone (ITCZ) and has already experienced increasing climate variability in the form of increasing extreme weather events such as severe storms, higher annual floods, more years when the unimodal rainy season fails, higher temperatures and more severe winds (Flint, 2007). The most serious impacts have been drought leading to food insecurity; overly high and damaging seasonal and flash floods damaging infrastructure, agriculture, lives and livelihoods; heat stress and other intensified health issues, which together have led to diminishing socio-ecological resilience. Droughts and floods have increased in frequency, intensity and magnitude over the last two decades and have adversely impacted on food and water availability and the sustainable livelihoods of rural communities (MTENR, 2007).

A number of studies have been conducted on climate variability and gender (Aboud, 2011; Goulden, 2006; Watson, 2001; Skinner, 2010). However, climate variability and gender has been less attended to in terms oflinking climate variability to the process of developing relevant environment and natural resource policies for natural resource dependent communities and most literature has lacked a reflection on theparticipation process of the natural resource dependent communities in the formulation and implementation of these policies especially at the local level and hence this study. The research questions for this study were (i) how has climate variability affected rural livelihoods and what has been the particular effects on gender roles? and (ii) were the local communities involved in the design of policies related to environment?. Therefore the aim of the study were (i) to provide evidence aboutclimate variability that has been experienced in the study area over a 40 year period 
(1970-2010) and (ii) relate climate variability to how the livelihoods of natural resource dependent women and men have been affected in the study area.

Patson and Karwat (2011) observes that policy making is the process used by governments to translate their political vision into programs and actions to deliver outcomes. It can be said that policy provides the framework and sets the parameters for planning. This paper further reviews the participation of natural resource dependent communities and gender considerations in the formulation of key policies such as the agriculture and environmental policies in the face of climate variability and how these policies have been implemented in practice at the very local levelin terms of a gender-responsive funding allocation and disbursement by government for adaptation activities.

\section{Methods}

The study was carried out between January, 2010 and December, 2011. Data collection tools included household survey, semi structured interviews, focus group discussions, key informant interviews, field assessments and desk studies.

\subsection{Description of the Study Area}

Sesheke district is situated at the south end of Western Province (Figure 1). It lies between $23^{\circ}$ and $26^{\circ}$ longitudes east and $15^{\circ}$ and $18^{\circ}$ latitudes south and shares borders with Kazungula and Kalomo districts of Southern Province (Figure 1). Within the Province the district borders with Kaoma, Shangombo and Senanga district.

The district lies in the Zambezi river basin and was used as a study area because of the different impacts of climatic stress that the district has experienced. Sesheke district lies in the agro-ecological Zone I which is characterized by the hottest and driest climatic conditions, with rainfall of less than $800 \mathrm{~mm}$ per annum and is categorized as semi-arid. It has a short growing period (season) of between 80 to 120 days. Rainfall is highly variable and unreliable within one rainy season, and between the years, putting pressure on agricultural development (CEEZ, 2009). Due to the history of climate variability in Sesheke district, the rural communities that depend on natural resources might be expected to be adapted to fluctuations resulting from a variable climate and women and men have been impacted differently by climate variability. The Zambezi river basin in which Sesheke district is located, has low "run-off efficiency" and a high dryness index thereby increasing its vulnerability to climate change (Riebsame et al, 1995). Sesheke is sensitive to climate warming as it receives considerable sunshine and high daytime air temperatures (Riebsame et al., 1995), making it the subject of high rates of evapotranspiration. 


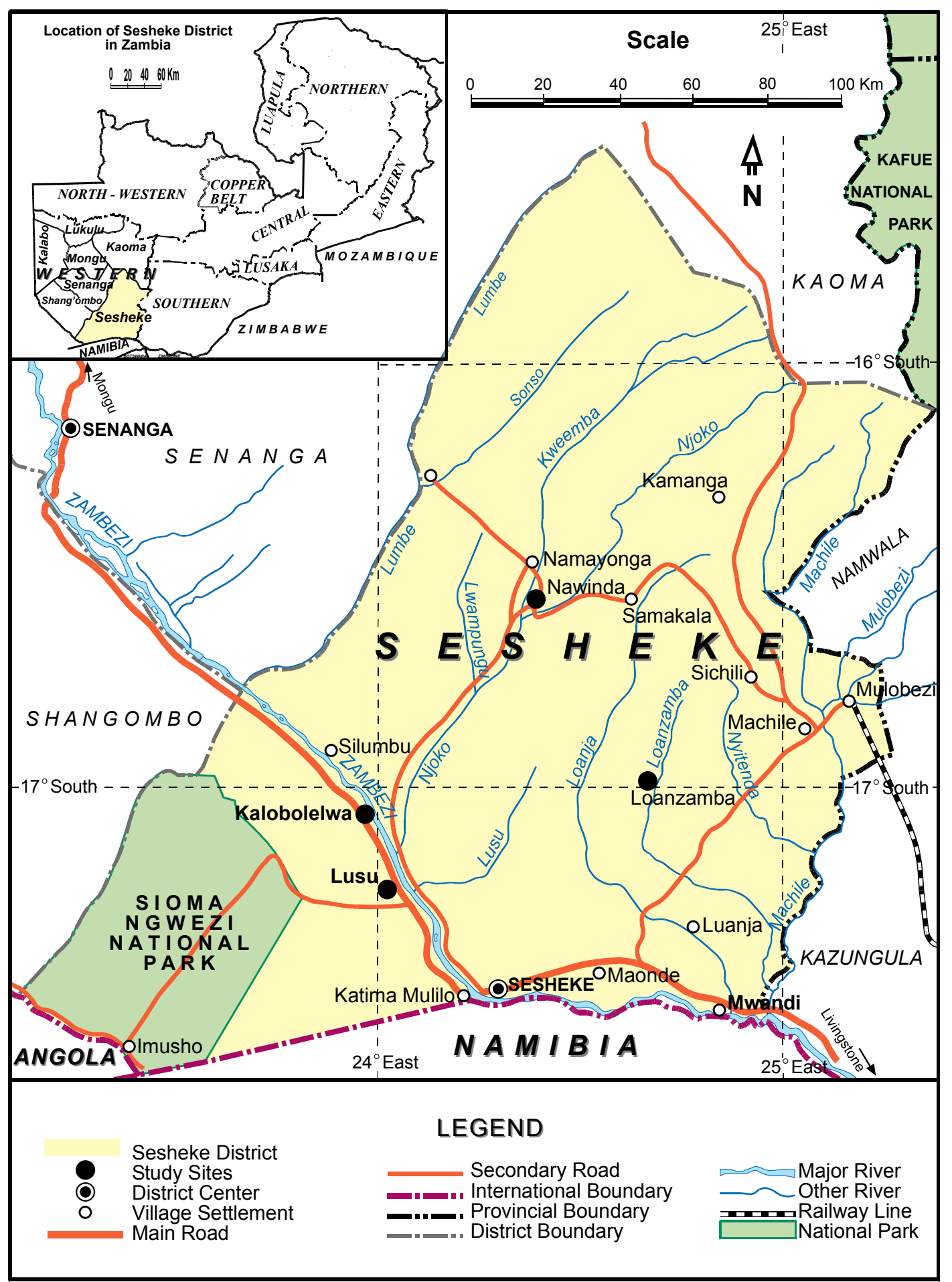

Figure 1. Location map of Sesheke District in western province of Zambia

\subsection{Research Design}

In order to seek insights about the evidence of climate variability and its link to gender and livelihoods of natural resource dependent communities as well as the aspects related to policies, detailed empirical research was needed in a specific geographical context. For this reason, a case study approach was used. This study involved the collection of both quantitative and qualitative data through the use of household sample surveys through questionnaires, focus group discussions, semi structured interviews, and direct observations using field transects. 


\subsection{Sampling}

Four wards also referred to as village settlements were selected and the selection criteria was that the four village settlements were located across Sesheke District in order to contribute to the spatial representation of the study area. Two of these village settlements are along the Zambezi river on the western part of Sesheke district, namely Kalobolelwa and Lusu, one is on the eastern part of Sesheke in the upland, namely Loazamba and one village settlement in the central part of Sesheke namely Nawinda. In this study, a household was the unit of analysis. These four village settlements were used for the household survey out of a total of 20 wards or village settlements. According to the Central Statistics Office (2004), Kalobolelwa had 875 households, Lusu 792 households, Loazamba 608 households and Nawinda 849 households. This gave a total of 3,124 households, from which a 10 $\%$ sample was selected. The selection of the households was done using systematic sampling with a random start following approximate straight lines in the villages with an interval of households determined using the formula $\mathrm{N} / \mathrm{n}$ (Conway, 1968), where $\mathrm{n}$ is the number of households to be sampled and $\mathrm{N}$ is the total number of households in a village. The proposed sample size was adequate and representative to capture the data needs for this study. This is consistent with Silk (1979) advice that an ideal sample size should at least be $10 \%$ of the target population.

\subsection{Data Collection}

The study utilized both quantitative and qualitative data. Data collection comprised household survey, field transects, individual and group interviews, focus group discussions, key informant interviews, observations and informal discussions. A semi-structured questionnaire was administered to each of the sampled households, with the head of the household as the targeted respondent. Where the head was not available, every effort was made to interview any adult household member who was knowledgeable about the general livelihood of the household.

The household was used as the unit of analysis for the sample survey. The gender aspects were captured by allowing both husband and wife if present to make contributions to the answers or allowing other members of the households to make contributions to the discussions. Data that was collected during the household survey included information on how the livelihood activities were distributed between men and women, changes that have occurred in the rainfall pattern, crop harvesting trend, land use changes that have taken place, availability and accessibility of natural resources especially fuel wood, distances covered to access firewood, changes in livelihoods linked to climate variability. Other data included questions on environmental and agricultural policies that there were aware of and if they had participated in the formulation of these policies.

The household survey was supplemented by semi structured interviews which were conducted with relevant government institutions both at national and district levels and with International and national NGOs. A number of organizations were identified as being important to this research work. These included government Ministries such as the Ministry of Lands, Natural Resources and Environmental Protection, Ministry of Agriculture at national level and Government Departments at district level included Environment and Natural Resources Management Department, Forest Department, Fisheries Department, Department of Agriculture, Central Statistics Office, Meteorological Department, NGOs working in Sesheke district, Community Based Organizations (CBOs). Information on the agriculture and environmental policies was obtained from the Ministry of Agriculture and Ministry of Lands, Natural Resources and Environmental Protection respectively. In addition, key informants were interviewed on how these policies have affected people's livelihoods in relation to climate variability. The research participants were selected on the basis of the role they had in the organization and in most cases the semi structured interviews were targeted at the heads of the various organizations including the technical people who worked in these targeted organizations. Key informant interviews were done with as many people as possible until a point was reached where I could no longer get any more new information and considered this as the saturation point.

Focus Group Discussions were also used as a data collection tool where discussions were held separately with elderly men, elderly women and a combination of elderly men and women. Focus Group Discussions generated information such as history of the area, geography, natural resources, land use types and climate change in the area. The focus group discussions were done with headmen locally known as indunas, women only group, men only group and other group discussions had a combination of both women and men as well as the youth. The segregation of the groups was done in order to allow the discussants freedom to discuss issues in an open and free environment as they were amongst their peers.

Four transect walks following compass directions of north, south, east and west were used for collecting some aspects of the physical data to confirm results from the interviews and focus group discussions in the four selected village settlements. These transects were for the purpose of observing the natural resources, land use, crops cultivated and livelihood practices in the study area.

Since studies of climate change involve analysis of historical climate data, the main source of climatic data was the 
Meteorological Department which has meteorological stations in Sesheke District and provided data on rainfall and temperature. This data was then used to determine if there were significant changes in rainfall and temperature as well as trends.

Data on historical land use and changes in forest cover was obtained from landsat images available from 1973 from the archives in the USA using the website www.usgs.org and aerial photographs. The forest cover change was done in order to determine the percentage change in forest cover that has taken place.The author tried to obtain some agriculture data from the Department of Agriculture at district level and only managed to get data for maize and was informed that the data for the other crops was not readily available and therefore relied on the household survey that was supplemented by key informant interviews. The author also tried to source for satelite images to examine crop area change in the study area but again these were not readily available.

\subsection{Data Analysis}

Data from open-ended questions in the sample survey, group discussions, observations and semi-structured interviews was analysed qualitatively to explain patterns/trends that were observed in the quantitative data. Qualitative data was read with an eye for themes, categories, patterns and relationships that were emerging across the data from the transcripts from individuals, group interviews and responses to open ended questions from questionnaires. The data was then summarised for key themes that emerged. Some of the qualitative data was used to generate annual time series trends generated by focus groups. The time series data was then used as descriptive evidence for the changes that have taken place in the study area.

Quantitative data analysis was done using the software Statistix 9.0. Preliminary analysis involved displaying the data in simple formats by producing summary statistics of a range of variables displayed in tables or graphically.

Analysis of Variance (ANOVA) was used to determine if there has been significant changes in rainfall and temperature in Sesheke district over the past 40 years. Changes in forest cover was determined by obtaining Landsat images available from the archives in the USA using the website www.usgs.org and aerial photographs. The forest cover change was done in order to determine the amount of change in the forest cover.

\section{Results and Discussion}

\subsection{Rainfall and Temperature Variability}

The rainfall pattern of Sesheke district has been highly variable in the forty year period between 1970 and 2010 as can be seen in Figure 2.

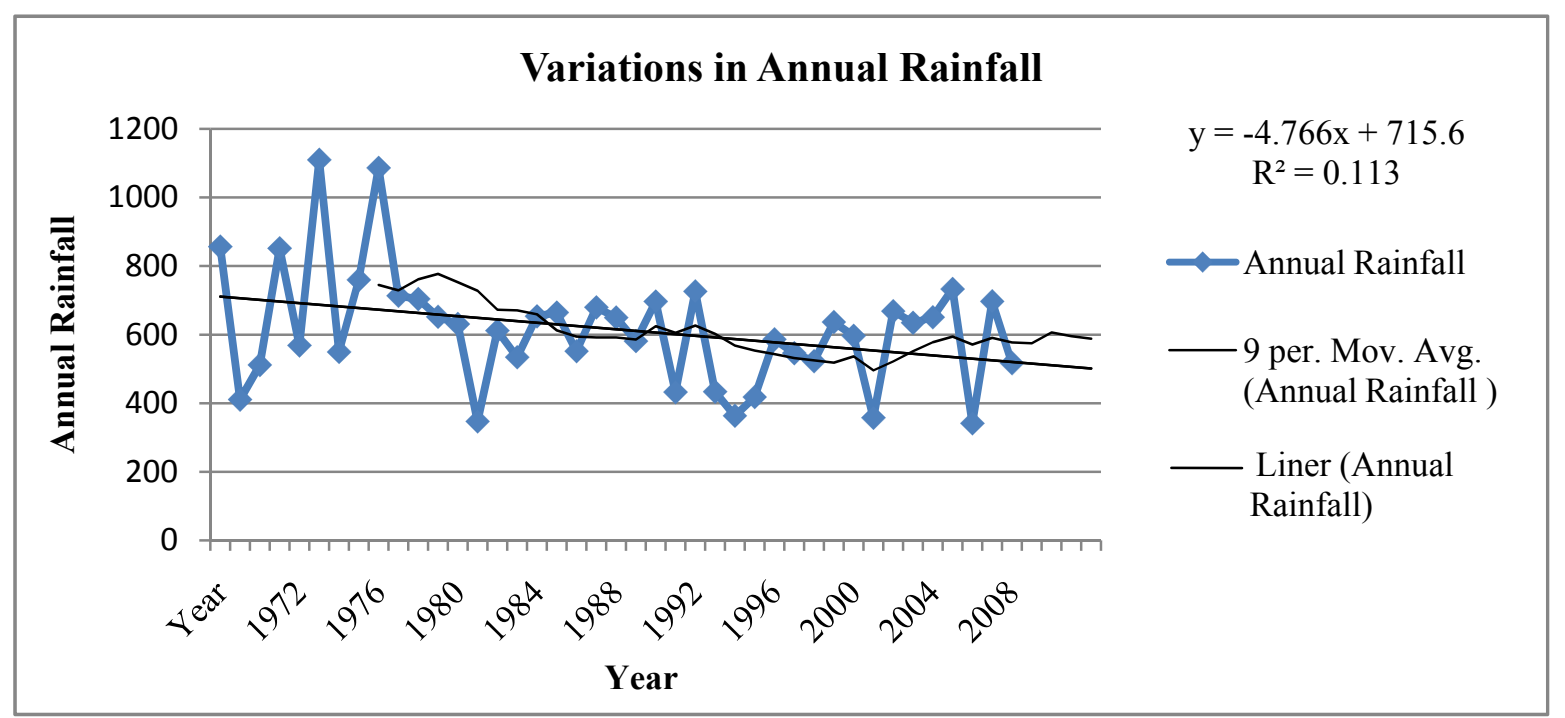

Figure 2. Annual rainfall variations

Analysis showed that there has been a significant reduction in the annual rainfall (Fisher distribution, $\mathrm{F}=4.34$, probability, $p<0.05$ ) over the 40 year period. The linear regression line confirmed a downward trend in annual rainfall. The ANOVA results and down ward trend of rainfall conforms with the results from the sampled households as well as key informant interviews where $99 \%$ of the respondents indicated that rainfall has been 
erratic in previous years and very unpredictable. The respondents observed that the rain season always delayed to start (December) and that the rain season ends very early around March. The unreliable rainfall pattern had negatively affected the productivity of the forests as well as the local people's agricultural livelihood which is very much dependent on rainfall. The mean rainfall over the 40 year period had been $611.11 \mathrm{~mm}$.

As for temperature, the ANOVA results have revealed a significant increase in maximum temperature $(\mathrm{F}=5.38$, $\mathrm{p}<0.05$ ) observed in the study area over the 40 year period. The time series graph (Figure 3 ) also showed a generally increasing trend in maximum temperature over the study period.

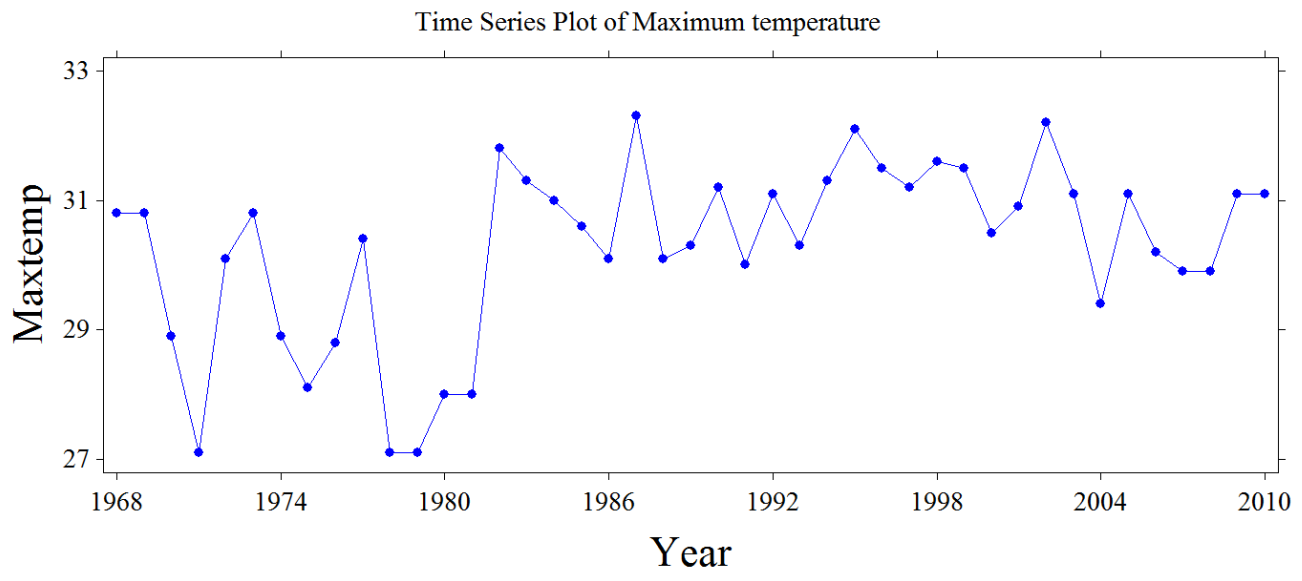

Figure 3. Time series plot of maximum temperature

Minimum temperature however showed no significant change over the last 40 years in Sesheke district $(\mathrm{F}=0.16$, $\mathrm{p}>0.05)$.

\subsection{Drought and Crop Production}

The manifestation of climate variability through drought in the study area has affected both men and women by forcing them to adapt to climate variability by using means such as changing crops. ANOVA results indicate that there has been a significant decrease in the main staple food crop maize production over the years $(\mathrm{F}=40.47, \mathrm{p}$ $<0.05)$. Maize was observed to cover the largest harvest area and almost $50 \%$ of the total cropped area according to key informant interviews with department of agriculture officers. The study area's level of dependence on maize made most households vulnerable to climate variability since maize is highly vulnerable to climate fluctuations because its phenology is sensitive to changes in moisture and temperature. Over $40 \%$ of the people indicated a shift towards drought tolerant crops such as cassava, millet and sorghum. Other people have also majored into growing early maturing maize varieties. Mostly men were responsible for providing cash income and thus preferred to raise cash crops like maize. Over $51 \%$ of the people indicated that they have had to vary the different sowing as well as harvest dates in order to spread the risk in case of poor or inadequate rainfall. The household survey revealed that women cultivated a wider range of crops whilst men on the hand hand cultivated a narrower range of crops than women and therefore women felt to have benefited more from the change of crops since women are the custodians of food security at household level.

The adapative capacity of the majority of the local people in the study area has depended on a number of factors such as economic status, health, education, information, skills and access to assets and all these factors have not been gender neutral. Over $80 \%$ of the women in the study area were of a low economic status with inadequate education and lacked access to assets as well as information and skills as compared to their male counterparts leaving women to be more vulnerable to the effects of climate variability. Over $60 \%$ of the people interviewed indicated that there was unequal access to and control over assets with men dominating and leaving the women with less adaptive capacity. Although the women have less adaptive capacity, they have continued to play an active role of their productive role by securing food and a livelihood for their households.

\subsection{Floods and Livelihoods}

Climate variability also exhibited itself through floods and again this affected both men and women in the study area. The floods impacted households in particular as well as communities in general. Over $50 \%$ of the 
interviewed households indicated that they have experienced an increase in flooding over the years. This was also in tandem with the information (Table 1) that was obtained from key informant interviews where the respondents indicated an increase in the amount of flood occurences.

Table 1. Flood occurences in the study area

\begin{tabular}{|c|c|c|}
\hline Flood Year & Description & Effect \\
\hline \multirow{3}{*}{ 1972/73 } & \multirow{2}{*}{ Heavy rains/floods } & Damage to to crops and bridges and decline in crop yield \\
\hline & & Contamination of drinking water \\
\hline & \multirow[b]{2}{*}{ Heavy rains/floods } & Damage to crops \\
\hline 1998 & & $\begin{array}{l}\text { Damage to infrastructure such as bridges, community } \\
\text { schools and churches }\end{array}$ \\
\hline 2008 & Excessive rainfall & Damage to crops and decline in crop yields \\
\hline
\end{tabular}

The respondents provided details on how the floods affected them. The impact of floods on livelihoods and adaptation were then summarised into direct loss and indirect loss. The direct loss included loss of livelihoods for over $70 \%$ of the households where flooding mostly led to widespread damage to crops and also resulted in loss of livestock. Crop losses was said to have been further intensified by transport problems due to flooded roads and damaged road bridges. Most respondents indicated that they had also suffered stress and anxiety during the flooding period and this was classified as part of the indirect loss. The women (over $70 \%$ ) bore the brunt of the disruption by floods of normal livelihood by having to walk long distances for collection of safe drinking water. Other women indicated having to manage in alternative ways such as collecting flood water and waiting for the sediments to deposit at the bottom and later use the water for drinking and cooking and others would store rain water to use for drinking. Due to poor crop yields, the prices of basic food items generally multiplied with severe stress imposed on the poor women and their families. To save on costs, most of the family members had to reduce on their food intake particularly the women. Many of the women indicated cutting back on eating three meals a day to once or twice a day. Some women would even sacrifice their food and eat less just to ensure that their children ate something no matter how little. Some households tried to survive by selling household assets such as poultry and livestock and most women indicated that the women's assets such as poultry were sold first than other items in order to try and manage during the flood period. Though it was evident that there was loss in crop revenue and damage to infrastructure, it was difficult and challenging to estimate or quantify the direct economic losses due to non availability of data from households or even key informants at that time.

With the information that was provided by both households and key informants, it can generally be said that floods exhibited social, economic as well as environmental consequences and this reduced the adaptaive capacity of the natural resource dependent communities especially the women in the study area and negatively affected their livelihoods.

\subsection{Forest Cover Change}

Forest cover change analysis using satellite images was conducted and supplemented by results from both key informant interviews as well as household interviews. The results for the forest cover change reveal a decrease in natural resource assets such as forest where the forest resource base had reduced by $40 \%$ between the year from 1990 and the year 2000.

This was confirmed by the household survey results on land use change which had $54.8 \%$ of the respondents indicating that most forests had been cleared to pave way for agriculture, $33.3 \%$ indicated that forests were being cleared for settlements by both the locals and those who came from other places to settle in the study area and only $7.4 \%$ indicated that forests had been cleared for infrastructure developments such as building of schools, health centers and roads.

The findings from the household survey and key informant interviews indicated a reduced trend in forest cover and attributed this to over exploitation of forests by the local people as an alternative source of livelihood in the face of poor harvests due to many factors and one of them being inadequate rainfall and poor soils. Forests had to be cleared in order to pave way for agriculture extensification so as to spread the risk of poor harvests due to poor rains whilst others being mostly men had resorted to charcoal production as an alternative livelihood in the 
face of poor harvests due to climate variabailityand all these factors have put pressure on the forests.
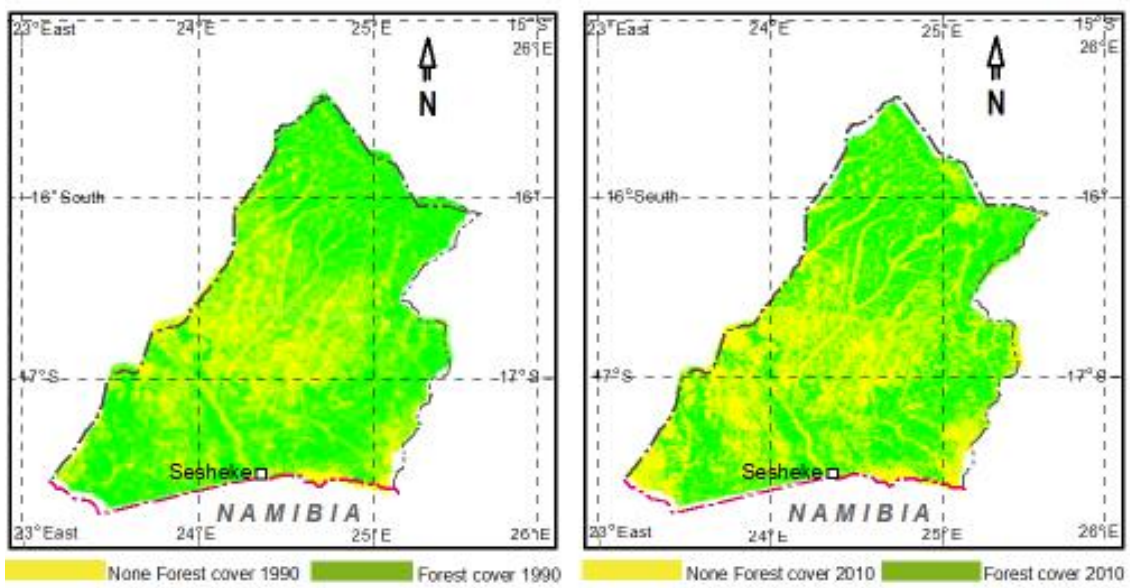

Figure 4. Forest cover change in Sesheke district

The high demand for agricultural land had led to the opening up of forested area for agricultural expansion. The increased demand for agricultural land has also led to encroachment into gazetted forest reserves. Transect walks through 10 out of the 28 national forests in the district revealed extensive encroachment representing $35 \%$ level of encroachment where the encroachers where freely practicing farming in the forest reserves.

The reduction of forest cover of $40 \%$ has presented a challenge to both men and women but especially women have been affected to a larger extent. Over $97 \%$ of the households in the study area rely on firewood as a source of energy for cooking and heating. Firewood collection represents one of the greatest women's labor constraints arising from the gender division of labor which traditionally has allocated the responsibility of firewood collection to women. This therefore means that firewood collection for domestic use has mostly been done by women and girls. The majority (89\%) of thewomen indicated that they have to bear the burden of walking long distances of between 3 to 8 kilometers from the safety of their communities in search of preferred firewood species. This has in turn increased their work burden, limited time available for food production and preparation and has also reduced their participation in income generating activities as well as educational opportunities.

Although there wasa presence of woodlands near houesholds, $58 \%$ of the women indicated that the remaining tree species that were nearby were not suitable for firewood as they took so long to light and easily burned out and released a lot of smoke forcing the women to walk the long distances in search of firewood species that were easy to light, took long to burn out and released less smoke.

\subsection{Agricultural Production}

The results $(80 \%)$ have revealed that the roles of men and women in agricultural production are well defined with mostly men being responsible for land clearing and preparation and women being responsible for planting, weeding, harvesting and post harvest activities. The results were slightly different for female headed households who indicated that women were generally responsible for land preparation, sowing, weeding, crop maintenance and harvest, and were almost exclusively responsible for growing food crops for the family. It was observed that men participated heavily in the sale of the crops after harvest. The efforts ofboth women and men in food and agricultural production has been hampered by unreliable rainfall, poor road network and lack of markets.

The majority of the people (56\%) viewed agriculture as a pathway out of poverty for women, but because of women's limited access to essential production resources such as fertile land, labor and inputs, women's role in agriculture was observed to be restricted to producing subsistence food crops with low potential to generate income. Out of total respondents, $36 \%$ of the respondents indicated that prospects for women to expand their incomes through alternatives such as seasonal migration or other means outside agriculture were limited due to the fact that women's mobility was usually more constrained by social and cultural norms. It was also observed that $42 \%$ of the women more than men spent their incomes on food, with consequent improvements in household food security even in the face of climate variability. 
One of the key elements in agricultural production is seed. Over $71 \%$ of the respondents indicatedthat all seed used to produce staple food crops in subsistence systems came from local seed systems as opposed to formal seed systems which was responsible for the flow of improved and hybrid seeds. Local systems were indicated as being responsible mostly for the flow of traditional seed. The respondents indicated that an important reason for relying on local seed systems was that small scale farmers especially women, often grew a diversity of crops to minimize the risk of total crop failure and food insecurity in case of drought. Gender dimensions manifested itself in the seed production as well as distribution. Mostly women were in charge of selecting and storing seed of many traditional food crops which were valued for specific attributes such as being cheaper and being adapted to local conditions and easier to obtain.Traditional seed varieties has been important in the face of climate variability as they have beenwell adapted to specific environments, they however have faced a number of constraints and these traditionalvarieties continue to be lost over time due to partly drought, introduction of improved hybrid seed varieties and policy shift which has consequently lowered the adaptive capacity of the natural resource dependent communities in the study area. For example, the policy by the Food Reserve Agency to stop buying colored maize from farmers has affected the availability of indigenous early maturing colored maize seed varieties. Traditional seed varieties have been in existence over time immemorial. For instance colored local maize has always been cultivated until white maize took over following its introduction and production stimulated chiefly by the demand of the export market and subsequently by the local policy shifts against colored traditional local maize. This shift in policy can be said to have eroded to some extent the local seed bank over time and can be said to have influenced negatively the adaptation strategies of the local people. Most women in the study area have had to suffer at the hands of this policy shift as they did not have the financial muscle to purchase the improved hybrid seeds and most often had to recycle the hybrid seeds which resulted in loss of vigor for the hybrid seeds over time. Therefore women felt that their adaptive capacity was reduced because they did not have extra incomes to purchase the hybrid maize seeds and since women are the custodians of food security, this policy shift was said to have affected their food security situation. The policy shift also served as a disincentive to men who could no longer keep the local varieties as would have no guaranteed market to sale their local colored maize other than FRA.

\subsection{Other Changes in Livelihoods}

An analysis of the livelihood history revealed that there are a number of livelihood activities that have tremendously reduced. About $92 \%$ of the households interviewed indicated that the natural resources such as forests and fish stocks in the study area had been decreasing.Respondents representing $15 \%$ out of which $12 \%$ were men had migrated from their original village to other villages as a way of securing off farm employment or doing what is termed as peace work in other areas and the women that were left behind to labour on increasingly unproductive land while being responsible for househod and family welfare as was also observed by Petrie (2008).

Both women and men have played an important role in supporting their households and communities to develop resilience and adapt to climate variability. Women participated in the gathering of forest products for fuel, fencing, food for the family, fodder for livestock as well as collection of medicinal plants when the need arose. Mostly men were involved in timber extraction and the use of non timber forest products (NTFPs) for commercial purposes. There were more women $(61 \%)$ compared to the men $(39 \%)$ who indicated that due to natural resources being far and scarce, they have had to walk long distances to fetch for the valuable natural resources and to some extent the women felt that this limited their time to engage in decision making, income generating or community activities and therefore restricted their opportunities for empowerment. Due to this division in labour, most women were differently and dispropotionately affected by climate variability.

\subsection{Availability of Natural Resources}

The results reveal that due to drought and associated poor crop harvests, most of the natural resource dependent communities have had to rely heavily on natural resources as a means of alternative livelihood. Therefore the availability of the natural resources and their spatial distribution has also greatly reduced. Over $95 \%$ of the sampled households as well as the key informants observed that there had been a decreasing trend in the availability of natural resources such as fish, trees, timber, mushrooms, honey, fuelwood and medicinal plants. In terms of availability and access to water, the most common sources for domestic use are rivers and streams and wells. Over $70 \%$ of the households indicated the major source of water during the dry season is streams or rivers and some of them are seasonal whose water levels depended on rainfall amounts.

As a result of the decreasing trend in the availability of natural resources, there was also an increase in the distances that had to be covered to have access to the natural resources. Over $70.2 \%$ of the sampled households 
indicated an increased distance of about 4 to $5 \mathrm{~km}$ for them to access the various natural resources and the people that were mostly affected by this were women. Though both men and women have been affected by climate variability, it is women who mainly have suffered the adverse impact of climate variability. Through their gender roles as household producers, women have had to walk substantially longer distances and spend more time and energy in fetching basic necessities such as firewood.

Over $70 \%$ of the respondents indicated that although women and men play critical roles in managing natural resources, it is women's gender roles in a wide range of activities that make them the daily managers of natural resources; that is, to wisely handle and use natural resources. Through their roles in production, reproduction and community management women, more so than men, are supposed to have a greater influence on the use of environmental resources but unfortunately is not the case in the study area.

While climate variability has been a factor associated with the depletion of natural resources, rules and regulations by the Barotse Royal Establishment and Forest Department which has provided certain restrictions on the accessibility of the natural resources was also observed to be a major constraint for some households.

Due to the scarcity of some of these natural resources, the study area encountered some conflicts though minimal in the use of the village rangeland and forest by various households. A case in point involves a special type of grass locally known as Mufiyelo which is used for making traditional brooms. This grass is special because it is only found in one specific location. The traditional leadership had observed some conflicts amongst households over the accessibilty and ownership of this grass.

Climate variability has affected the availability of non forest products like honey and wild fruits. The reduced availability of honey was attributed by traditional beekeepers to drought which they said affected the flowering system of trees and consequently led to a lower honey production. Interviews with key informants from Forest Department and Department of Agriculture confirmed the observations of the traditional beekeepers. The key informants revealed that the beekeeping activity has suffered the colon colapse disorder where bees had been deserting the hives when they are unable to find sufficient quantities of pollen and nectar. Key informant interviews also revealed a reduced flowering of trees attributed to persistent drought and thereby affecting the production of wild fruits. The collection and sale of wild fruits has been dominated by women in the study area and most of them indicated that they no longer harvest adequate quantities of wild fruits for food, nutrition and income. Wild fruits have been important in relieving hunger periods in the agricultural cycle and provide seasonal income but all this has since reduced due to persistent drought.

\subsection{Policies in the Face of Climate Variability}

Zambia has a number of policies that have a linkage with climate change issues namely the Forest Policy of 1998, the Water Bill of 2010, the Agriculture Policy (2004) and the National Policy on Environment (2005). This study focussed mainly on two policies namely Agriculture and Environment Policy as they were closely related to issues of climate variability.

The environment policy provides for theintegration of gender, youth and children concerns in environmental planning decisions at all levels to ensure sustainable social and economic development as an integral component in gender and development policy.The guiding principle is that both women and men including the youth should play a key role in the sustainable utilization of renewable natural resources and other development programmes. The policy provides for the strategy of promoting the participation of the women and the youth in environmental management activities at all levels andrecognizes the importance of gender roles and gender analysis in environmental management in all training programmes, at all levels. The policy further encourages youth and women involvement in pilot projects in environment and natural resources programmes.

At the time of conducting this study, the Ministry of Lands, Natural Resources and Environmental Protection was in the process of developing a climate change policy. Key informant interviews indicated that gender will likely be addressed in the upcoming climate change policy. The key informant interviews revealed that the climate change policy will try to mainstream gender especially for the most vulnerable people who are the poor living in rural areas and thatgovernment was aware that the poor who form a majority of the country's population and usually live in rural areas are generally more vulnerable to climate change as their ability to cope with climate induced changes and disasters is compromised by their low adaptive capacity.

Zambia developed the National Agricultural Policy in 2004 whose overall aim is to facilitate and support the development of a sustainable and competitive agricultural sector that assures food security at national and household levels and maximizes the sector's contribution to Gross Domestic Product. In terms of food security, the policy provides to ensure for a dependable and efficient annual production of adequate supplies of cereals, legumes, 
roots and tubers, tree and plantation crops, horticultural crops, fisheries and animal products is maintained and sustained (MACO, 2004). The Policy outlines emergency preparedness that will be strengthened through the provision of timely early warning information, undertaking timely crop forecasting and creation and maintenance of strategic food reserves (MACO, 2004). The Agricultural Policy however does not address the gender dimensions with regards to adaptation of farmers to climate variability but provides for gender equity in resource allocation and access to agricultural services focusing on women and young farmers.

\subsubsection{Consultation Process With Rural Communities When Developing Policies}

The policy formulation process was participatory and consultative. The results from the household surveyrevealed that $8 \%$ of the local people in the study area were aware of the existence of the Environmental Policy as well as the Agriculture Policy and the related objectives of these policies. The same was the case with all the government Officers at the district level. 3\% of the rural interviewed households participated in the district consultative meetings that led to the development of these policies. The inclusion of the local people in the development of these policies provided an opportunity for both men and women to have their views, concerns as well as practical experiences be included in these policies. It was useful that representatives from the villages had their voices heard during the formulation of these policies as their livelihoods were the ones that were greatly affected by the impacts of climate variability. The key informants indicated that the government was aware that policies were neither effective nor fair unless they became gender aware and therefore recognized that development actors are women as well as men. This meant that greater gender awareness translated into recognizing that women have the right to be included in policy making and related decisions and to benefit from the policies equally. The government has been alive to the fact that ensuring adaptation to climate variability needed to take into account the participation of all stakeholders especially the natural resource dependent rural communities comprising of both men and women who also contribute to climate change responses in different ways and have different capabilities based on their respective knowledge and experiences.

\subsubsection{Implementation of the Policies}

Despite the increased recognition of the linkages between gender dynamics and agriculture, environment and climate variability, little progress has been shown in translating these into programs and actions at the local level. Whilst the local people were consulted during the formulation stage of these policies, the results from key informant interviews revealed an inadequate and unconsolidated approach to the implementation of the policies with most of the activities being very dependent on donor support by way of projects being piloted that lacked sustainability. It seems evident that the policies have lacked a consolidated implementation plan with no roll out plan.

Key informant interviews also revealed that there has not been any gender responsive funding allocation and disbursement from central government to the relevant government departments at district level that are entrusted to support adaptation measures to climate variability by natural resource dependent households in particular and communities in general.A review of the budgets of the department of agriculture and department of forestry revealed that the annual work plans and budgets were not developed with a gender focus in mind and lacked information on how women and men will be incorporated into the various proposed activities. Funding to the department of agriculture and forestry that are supposed to assist communities at district level with adaptation activities has been very poor. An analysis of the funding disbursement indicate that the department of forestry at district level received funding of not more than $10 \%$ of their total budget making it extremely difficult to carry out their activities. Given these results, there is need for government to address the poor funding to the districts for climate change activities and incorporate gender during the budget planning process as well as actual funding in order to support the livelihoods of the local people.

Key informant interviews reveal that institutional capacity for climate risk management preparedness strategies and for agro meteorological adaptation strategies to cope with the consequences of climate variability has been poor in the study area. The capacity being referred to is inadequate technical, financial as well as human capacity.

\section{Conclusion}

This research has revealed that the study area has experienced climate variability in form of droughts and floods and although this has affected the livelihoods of both men and women, women have been hardest hit. The adapative capacity of mostly women has been quite low dueto a number of factors such as low economic status, low education levels, lack of skills and lack of access to assets, all these factors have not been gender neutral.

Climate variability has contributed to a reduction in forest cover. The study has shown a reduction in forest cover 
which has partially been attributed to over exploitation of forests by the local people as an alternative source of livelihood in the face of poor harvests due to many factors and one of them being inadequate and unreliable rainfall and poor soils. This has also affected the availability of the natural resources as well as their spatial distribution which has greatly reduced. The study has revealed a decreasing trend in the availability of natural resources such as fish, trees, timber, mushrooms, honey, fuelwood and medicinal plants. The reduction in forest cover and non availability of natural resources has affected mostly women since they have to walk long distances to fetch valuable natural resources and increased their work burden, limited time available for food production and preparation and has also reduced their participation in income generating activities as well as educational opportunities. Though both men and women have been affected by climate variability, it is women who mainly have suffered the adverse impact of climate variability. Through their gender roles as household producers, women have had to walk substantially longer distances and spend more time and energy in fetching basic necessities such as firewood.

The study has also shown that a gender perspective has been an integral part of climate change thinking and policy in Zambia. The impacts of climate variability have not been gender neutral, and the government has recognized that policies cannot be effective unless they are gender aware, taking into consideration the different needs of women and men, the inequalities that compound the impacts of climate change for women and the specific knowledge women and men can contribute to solutions for adaptation and building resilience but has however lacked a gender responsive funding allocation and disbursement.

As a way of concluding, this paper notes that there are a number of areas where policy makers can intervene. There is need for the government to put up a consolidated implementation plan as a follow up to the policies and work out measures for sustainability instead of entirely depending on donor support. Donors should consider supporting civil society organizations both at local and national level to hold climate change related policy makers to account for their political commitment to gender equality. Given the strategic dependence of women and men's livelihoods on natural resources in the area, efforts will be required to implement effective and longer-term agro meteorologicalprograms to adapt production systems to climate variability. Multi-disciplinary institutional capacity is needed to develop local level analytical frameworks to provide sound practical guidelines for longer-term investment in food security related infrastructure for disaster mitigation at district level and for evolving livelihood adaptation strategies and risk management at local level.

The lessons derived from this paper are important not only for the case study area in particular but for many parts of Africa in general as there are indications that this is a similar experience in other parts of Africa as well. Other countries in Africa can use these findings for policy makers and donors to integrate the outcomes of this research into their policy planning, implementationand incorporate gender during the budget planning process and funds disbursements. Responses to climate change needs to be grounded in an increased understanding of the relationships between men and women at the household level and how these relationships are affected by, and influence responses to climate change.

\section{Acknowledgements}

Special thanks to the World Wide Fund for Nature (WWF) for the financial support for the research and Dr. Henry Sichingabula and Dr. Orleans Mfune for the useful comments.

\section{References}

Aboud, G. (2011). Gender and climate change. Institute of development studies.

Adger, W. N., Hughes, T. P., Folke, C., Carpenter, S. R., \& Rockstrom, J. (2005). Social-ecological resilience to coastal disasters. Science, 309(5737), 1036-1039. http://dx.doi.org/10.1126/science.1112122

Dankelman, I. (2010). Gender and climate change. UK.

Denton, F. (2002). Climate change vulnerability, impacts, and adaptation: Why does gender matter? Gender \& Development, 10(2), 10-20. http://dx.doi.org/10.1080/13552070215903

Ellis, F. (2000). Rurallivelihoods and diversity in developing countries. Oxford: Oxford University Press.

Goulden, M., (2006). Livelihood diversification, social capital and resilience to climate variability amongst natural resource dependent societies in Uganda. School of Environmental Sciences, University of East Anglia.

IPCC. (2001). Impacts, Adaptation and Vulnerability, Summary for Policymakers and Technical Summary of the Working Group II Report. Geneva: IPCC.

Mfune, O. \& Sakala, P. Gender and energy poverty in rural Zambia. Journal of Humanities. University of 
Zambia, Lusaka.

Ministry of Agriculture and Cooperatives. (2004). National Agricultural Policy. GRZ.

Ministry of Tourism, Environment and Natural Resources. (2007). National Adaptation Programme of Action. GRZ, Lusaka.

Ministry of Tourism, Environment and Natural Resources. (2009). National Environmental Policy. GRZ, Lusaka.

Parson, E. A., \& Karwat, D. (2011). Sequential climate change policy. Wiley Interdisciplinary Review: Climate Change (Jun 28, 2011, Online Edition). Wiley. http://dx.doi.org/10.1038/nclimate1290

Petrie, B. (2008). Gender and climate change, Regional report. Cape town: Heinrich Boll Foundation. http://dx.doi.org/10.1038/ncb0508-507

Riebsame, W. E. K. M., Strzepek, J. L., Wescoat, Jr., R., Perrit, G. L., Graile, J., Jacobs, R., ... Yates, D. (1995). Complex river basins. In K. M. Strzepek \& J. B. Smith (Eds.). As climate changes, International impacts and Implications. New York: Cambridge University Press.

Skinner, E. (2010). Gender and climate change - overview report. Institute of development studies.

Watson, R., T. (2001). Climate change synthesis report: contribution of Working Groups I, II, and III to the Third Assessment Report of the Intergovernmental Panel on Climate Change. Cambridge: Published for the Intergovernmental Panel on Climate Change Cambridge University Press.

World bank. (2009). Gender in agriculture source book.

\section{Copyrights}

Copyright for this article is retained by the author(s), with first publication rights granted to the journal.

This is an open-access article distributed under the terms and conditions of the Creative Commons Attribution license (http://creativecommons.org/licenses/by/3.0/). 